\title{
Federal Education and Switzerland
}

\section{Dear Readers,}

Federalism is a political system based on the distribution of power between the central authority and the federated authorities. They are seen as a single political force against the outside. According to the agreement between them, governances (states, provinces, cantons) are autonomous in their internal affairs (Ari \& Heiter, 2021). Switzerland is known for its strong democracy that has been exercised continuously for hundreds of years and as a country that has successfully applied federalism (Ari \& Schmitt, 2021).

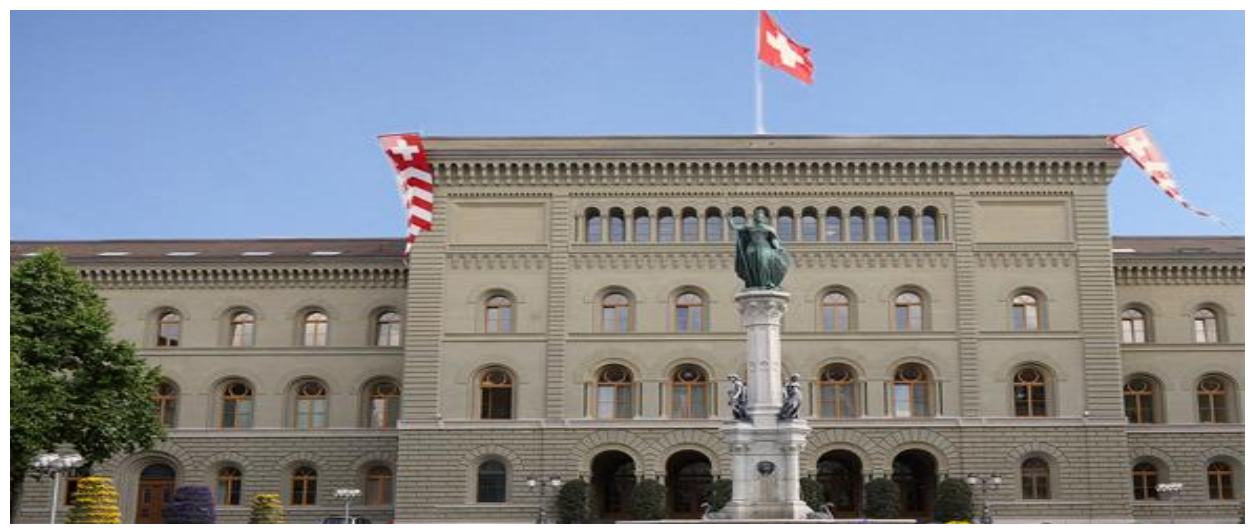

Figure 1

Federal Council (Swiss Confederation, 2021)

Swiss Federalism is the product of two centuries of development evolution from small independent states to a single modern state. There are 26 cantons, these are considered as states and the cantons are largely autonomous. Switzerland, with its long tradition as a federalist state that has successfully redistributed power, has a wealth of experience to offer other countries (Unifer, 2021). One of these experiences is the successfully applied federal education.

There are differences in education systems among cantons, as in many other fields. There is no general "Swiss Education System". The federal government lays down only certain basic rules in education. Each canton has a different education system and schools are subordinate to local governments in the cantons. Giving the cantons the right

Citation: Ari, A. \& Felder, F. (2022). Federal Education and Switzerland. International Journal of Instruction, 15(1), i-iv. https://doi.org/10.29333/iji.2022.1510a 
to determine their own school systems led to the development of different school systems in Switzerland. For example;

This federal country has three official and a semi-official languages, German, French, Italian and a little Romani are spoken. The cultural differences in the cantons such as speaking different languages have revealed different school structures. Having four different official languages and practicing these four-languages in all areas of life can be counted as perfect federal education example. Which language a canton speaks, education is given in that language in schools. Therefore, the language of instruction differs according to the canton.

During compulsory education, children learn one of the other languages spoken in other cantons. Although English education is in all schools, the choice of foreign language given in schools varies according to cantons.

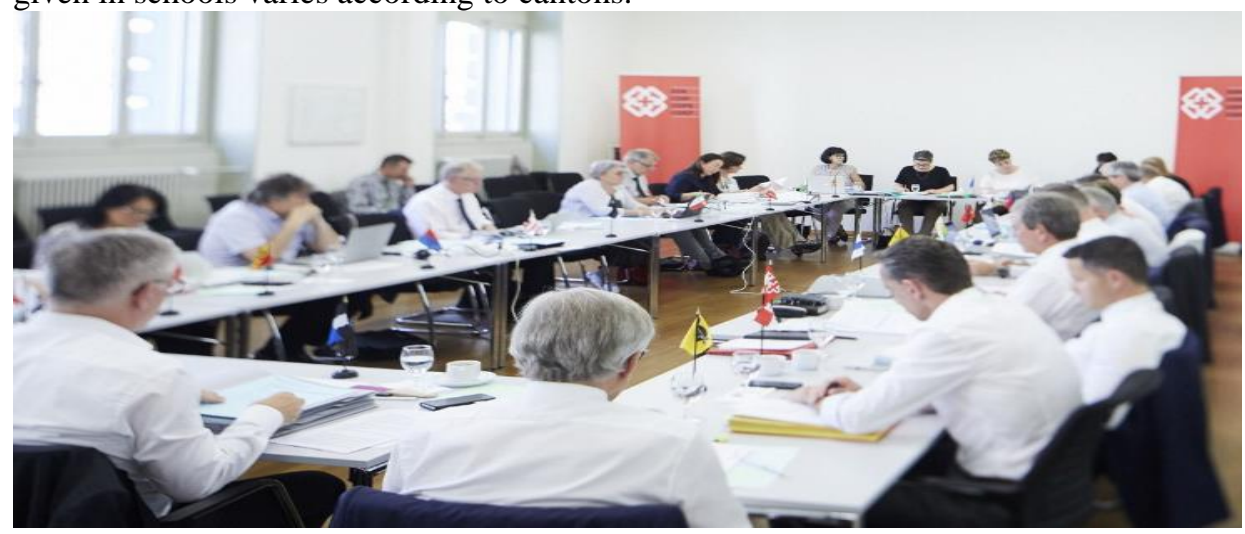

Figure 2

The Swiss Conference of Cantonal Ministers of Education (The EDK, 2021)

There is no Ministry of Education. As most of the responsibility for educational decisions is made by cantons and municipalities, the Swiss education system can not be managed by a single authority. The 26 cantonal ministers form The Swiss Conference of Cantonal Ministers of Education (The EDK). The members of the EDK come together on regular basis and discuss the future of Swiss education, find joint solutions for the entire country as regards important educational issues. It aims to ensure high quality, equity, permeability and mobility within the Swiss education system (The EDK, 2021)

The education system is largely financed by the cantons and municipalities themselves. The school year calendar, holidays, weekly lesson hours, course schedules, curriculums, management of schools, education period of schools may be vary between cantons. For example, primary school may last four years, five years or even six years depending on the cantons.

The university system gets its share from that federalized structure. There are only two federal institutes in Switzerland that can be accepted as the universities of the whole of Switzerland as they are administered and financed by the federal government. The other 
universities like Fribourg University or Bern University belong to that canton in which they are situated. University admission requirements may also vary from canton to canton.

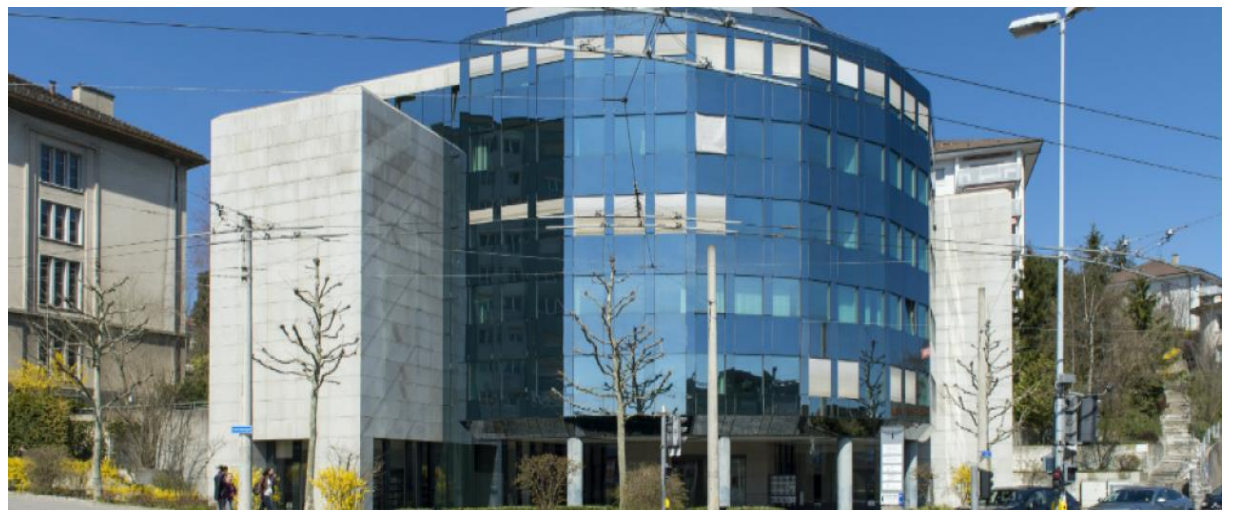

Figure 3

Institute of Federalism (https://www.unifr.ch/federalism/en/)

Researchers who want to learn more about this subject can find opportunities in Switzerland. One of them is the Fribourg University Federalism Institute. The Institute of Federalism successfully provides researchers and participants from different cultures with opportunities to research and receive education together (Ari \& Stöckli, 2021).

Sincerely,

Prof. Asim Ari

Editor in Chief

\section{Flavien Felder}

Guest Editor

Visiting Researcher/Lecturer at the Institute of Institute of Federalism

Federalism, University of Fribourg, Switzerland University of Fribourg, Switzerland

Email: asimari64@gmail.com

Website: http://www.federalism.ch

Email: flavien.felder@unifr.ch

Website: http://www.federalism.ch

\section{REFERENCES}

Ari, A. \& Heiter, Y. (2021). Federalism and Switzerland as a Federal State. International Journal of Instruction, 14(4), i-iv. https://doi.org/10.29333/iji.2021.1440a

Ari, A. \& Schmitt, N. (2021). Democracy Education in Switzerland, Known for its Strong Democracy: From the Editor. International Journal of Instruction, 14(3), i-iv. https://doi.org/10.29333/iji.2021.1430a 
Ari, A. \& Stöckli, A. (2021). Switzerland Case as an Example of Success in Multicultural Education: From the Editor. International Journal of Instruction, 14(2), iiii. https://doi.org/10.29333/iji.2021.1420a.

Federal Council (2021). Swiss Confederation. Retrieved from: https://www.admin.ch/gov/en/start.html (Retrieved December 15, 2021).

The EDK (2021). The Swiss Conference of Cantonal Ministers of Education. Retrieved from: https://www.edk.ch/en (Retrieved December 15, 2021).

Unifer (2021). Swiss Federalism. Retrieved from: https://www.unifr.ch/federalism/en/topics/chfederalism.html (Retrieved July 18, 2021). 